\title{
E-zines Silence the Brand Detractors
}

Barbara Briers, Siegfried Dewitte, and Jan Van den Bergh

Barbara Briers is a Ph D student in marketing, Siegfried Dewitte is Assistant Professor of marketing at the Department of Applied Economics, K.U.Leuven, Naamsestraat 69, 3000 Leuven, Belgium. Jan Van den Bergh is CEO of i-Merge (www.i-merge.net).

Correspondence concerning this article should be addressed to Barbara Briers, Department of Applied Economics, K.U.Leuven, Naamsestraat 69, 3000 Leuven, Belgium. E-mail: barbara.briers@econ.kuleuven.be; Tel: +32 1632 69 47; fax: +3216326732 .

\section{Acknowledgements}

The authors thank Nancy Geyskens, market research director of the NMBS (Belgian Railway Company) for her support in collecting the data, the students Marketing of the Katholieke Universiteit Leuven (2003-2004) for their valuable help in collecting the data and creating the e-zines. We thank i-Merge for the valued help in editing the e-zines and managing the data. We thank Kobe Millet for comments on an earlier version of this manuscript.

The first author acknowledges financial support by the Flemish Science Foundation (FWO) under grant G.0260.02 and by the Belgian Science Policy grant

CP01/151. The second author acknowledges financial support by the Flemish Science foundation under grant G.0391.03, and by the OT (university grant OT 03/07). The first and second author gratefully acknowledge financial support by CensydiamSynovate. 


\section{E-zines Silence the Brand Detractors}

In this paper we investigated whether a company's recommendation factor can be increased by opt-in e-zines. A sample of 817 railway travelers was interviewed on the train. Using Reichheld's (2001) recommendation index, respondents were categorized as brand detractors, passively satisfied customers, or brand promoters. Respondents giving permission $(n=555)$ received either none or three e-zines in a period of six weeks. Post-measurement results $(n=221)$ showed that the proportion of detractors was significantly lower among respondents who received the newsletters compared to those who received no e-zines. Personalization to the receivers' lifestyle, however, had a negative effect on recommendation. We conclude with managerial implications and suggestions for future research.

\section{THEORETICAL BACKGROUND}

Loyalty is a person's willingness to make an investment or personal sacrifice in order to strengthen a relationship (Reichheld, 2001). For a customer, this can mean sticking to a supermarket that offers him good quality even if this supermarket is on the other side of town but it can as well mean putting one's reputation at stake in recommending a product to colleagues (Reichheld, 2001). Managers as well as researchers know that loyalty in general and positive product recommendation in particular increases profitability. Loyal customers talk up a company to their friends, family, and colleagues. Customers continue to purchase those products that satisfy them and influence the brand perceptions of those with whom they communicate (Richins, 
1983). In this paper, we explore to what extent electronic permission marketing can influence a customer's inclination to recommend a product to others.

According to Reichheld (2001), spontaneous product recommendation among customer networks is an important marker of company success. Reichheld identified the difference between the percentage of brand promoters and the percentage of brand detractors as a strong predictor of long-term company success. The brand promoters are the customers who are enthusiastic enough to refer a friend or colleague. The brand detractors are the customers who are dissatisfied enough to spread negative word-ofmouth. Reichheld called this difference a company's recommendation factor. Because the recommendation factor is a compound measure (i.e. the difference between brand promoters and brand detractors), we next focus on the two parts of the recommendation factor separately.

The recommendation factor is positively influenced by the percentage of brand promoters. He stated that recommendation is one of the best indicators of loyalty because of the customer's sacrifice in making the recommendation. Brand advocates put their reputation on the line and will do so only if they feel intensely loyal. As "recommending" customers can bring in new customers at no charge to the company, a convenient path to profitable growth may lie in a company's ability to get its loyal customers to become its marketing department.

The recommendation factor is negatively influenced by the percentage of brand detractors. Detractors' responses include (a) switching brands or refusing to repatronize the offending store, (b) making a complaint to the seller or to a third party, and (c) telling others about the unsatisfactory product or retailer (Richins, 1983). Indeed the flip side of promoters' recommendations to friends or family is that detractors can spread negative word-of-mouth about a company's performance. Negative word-of- 
mouth can have detrimental effects on a business, in particular since several researchers have found that consumers seem to place more weight on negative information as opposed to positive information (e.g. Lutz, 1975; Wright, 1974; Fiske, 1980). For example when receivers of negative word-of-mouth communication attribute the negativity of the message to the brand, brand evaluations will become more negative (Laczniak, DeCarlo, and Ramaswami, 2001). In sum, we conclude that the recommendation factor can be enhanced by increasing the percentage of promoters and by decreasing the number of detractors. In this paper, we investigate the potential of permission marketing in turning non-promoters into promoters or in turning detractors into non-detractors.

Countering a damaged reputation requires a company to seek growth through expensive shortcuts such as massive price cuts or other appealing incentives that will persuade skeptical customers to repurchase a product. Besides price cuts and appealing incentives a company might reach out for diverse communication techniques to restore one's reputation. Mass communication and the proliferation of ads causes consumers to avoid ads in traditional media and on the internet: The so-called cluster-bomb approach of ads on the internet has been cited as an important cause of the trend toward declining consumer responsiveness to internet ads (Cho and Cheon, 2004). There is a potential for information overload in the information-rich and sometimes poorly organized environment (Dholakia and Bagozzi, 2001). A customer related marketing strategy might be more efficient in convincing skeptical customers to remain loyal and repurchase a product or service. Particularly permission marketing, which allows the prospect to control and shape the communication received from marketers, might cause less resistance among detractors. According to Soars (2001), consumers are increasingly looking for personalization and for e-tailers to remember past interactions. 
On the other hand, consumers also desire the opportunity to have control over the information they receive and want the chance to exercise an opt-out privilege.

\section{THE PRESENT STUDY}

A wide variety of e-commerce marketers is already implementing permission based electronic newsletters or so-called e-zines as a way to inform customers about promotions or special services, to acquire new customers, to increase sales, and most importantly, to develop a "loyal" long-term relationship with their customers that might increase positive recommendation or decrease negative word-of-mouth. Nevertheless, to date, little research has been done that measures the impact of these e-zines on customer recommendation behavior. In this paper, we want to investigate whether sending e-zines can enhance a company's recommendation factor or make it more robust to external influences.

We obtained the recommendation factor according to Reichheld's (2001) guidelines. Reichheld proposed to substitute a single question, "How likely is it that you would recommend company X to a friend or colleague?", for the complex box of the typical customer satisfaction survey. Reichheld developed a scale for this question where ten means "extremely likely to recommend", five means "neutral", and zero means "not at all likely to recommend". Working with this scale, Reichheld obtained three empirical clusters based on customer referral and repurchase behaviors: "(Brand) promoters", the customers with the highest rates of repurchase and referral, gave ratings of nine or ten to the question. The "passively satisfied" logged a seven or an eight, and "(Brand) detractors" scored from zero to six. In our research, this Reichheld's 
recommendation index was measured twice to capture the effect of e-zines on customers' loyalty.

In our research volunteers "opt in" by offering their e-mail address to a market researcher after a short interview on the train. Some of them receive e-zines and others do not. Each e-zine consists of two business relevant articles and one lifestyle article. We investigate whether these e-zines have an impact on customers' inclination to recommend the product to others in light of their initial recommendation index. Our central hypothesis is that the application of e-zines will increase Reichheld's recommendation factor. Further, we will look at the four possible drivers of this expected e-zine effect. Brand promoters receiving e-newsletters might be less likely to turn into passively satisfied customers (1). Passively satisfied customers receiving enewsletters might be more likely to turn into brand promoters (2), or less likely to turn into brand detractors (3). And finally, brand detractors receiving e-newsletters might be more likely to turn into passively satisfied customers (4). These four possible effects have in common that they would increase the overall recommendation factor.

In addition, we wanted to examine whether adjusting the content of the newsletters to the receiver's lifestyle could bring about additional effects on the recommendation factor. Hence in this research, we personalize the newsletter by including one article in line with the receivers' lifestyle and not in line with the receivers' interest in the product or service of the company. Although targeting and personalization strategies result in higher customer response and retention rates, permission marketers also must produce appealing and above all, relevant communications to gain and keep loyal consumers (DuFrene, Engelland, Lehman, and Pearson, 2005; Tezinde, Smith, and Murphy, 2002). Customers tend to sign up for more services than they are interested in, which creates the need to cut back in the numbers 
of e-mails they receive. Because of this competition, message relevance is extremely important in promoting effective e-mail marketing (Krishnamurthy, 2001). A strongly (lifestyle) personalized e-zine therefore may be perceived as being less relevant with respect to the company's business. As Fletcher and Peters (1997) point out: "The frustration experienced by consumers in providing personal information to a firm when this information appears to be disregarded and/or unrelated to the product/service offerings made by the firm, is a potential threat to relationship development which must not be overlooked or treated lightly". Moreover, in the context of persuasion knowledge (Friestad and Wright, 1994), a strong (lifestyle) personalized e-zine may be interpreted as a marketer's persuasion attempt and therefore slacken the effect of e-zines on customer loyalty.

\section{METHODOLOGY}

\section{Design}

Initially, 817 railway travelers (56\% men vs. $46 \%$ women, of which $81 \%$ between 23 and 40 years old) answered Reichheld's recommendation index in a short interview on the train (i.e. Phase 1). Respondents were invited to "opt in" for receiving further e-mails by providing the market researcher with their e-mail. Sixty-eight percent of the initial respondents gave permission to use their e-mail address. Of the remaining 555 respondents, 137 were randomly assigned to the control condition and did not receive any newsletters; the other 418 participants were assigned to the experimental condition and received three e-zines in the following 6 weeks. The newsletters contained three topics. Two topics were related to the railway, the third topic was a 
lifestyle topic that was either personalized in line with the respondent's lifestyle or not. After this period, the total sample received a closing e-mail with the second Reichheld's recommendation index measure (i.e. Phase 2).

Procedure

In Phase 1 railway passengers traveling to or from Brussels were approached to complete a written questionnaire. This questionnaire included Reichheld's recommendation index, questions concerning the respondent's traveling behavior, personal attitudes, and demographics. The traveling behavior questions probed (1) the specific train ticket, (2) the reason for traveling, and (3) the frequency of traveling by train. The personal attitudes section latched onto (1) the respondent's favorite radio channel, (2) favorite TV channel, (3) favorite movie genre, (4) favorite sports, and (5) the respondent's hobby. Each question had five possible reply categories. The attitudes were used to personalize the e-zines, as described below.

Throughout the 6-weeks campaign three e-zines were sent every fortnight in the name of the Belgian railway company NMBS. A professional online ad agency created the e-zines. Every newsletter contained three teasers with a link to an article. The first article described new or less known services of the railway company. A second article discussed investment projects in the area of Brussels. The third and final article dealt with lifestyle issues. 
Table 1 Content of the three E-zines

\begin{tabular}{|l|c|c|c|}
\hline E-zine & $\begin{array}{c}\text { Article 1: } \\
\text { Services of the company }\end{array}$ & $\begin{array}{c}\text { Article 2: } \\
\text { Projects in Brussels }\end{array}$ & $\begin{array}{c}\text { Article 3: } \\
\text { Lifestyle }\end{array}$ \\
\hline E-zine 1 & $\begin{array}{c}\text { Train ticket purchase on } \\
\text { the internet }\end{array}$ & $\begin{array}{c}\text { Modernization of Brussels } \\
\text { central station }\end{array}$ & Sports \\
\hline E-zine 2 & $\begin{array}{c}\text { Electronic moneybox for } \\
\text { tickets }\end{array}$ & $\begin{array}{c}\text { Express trains in the Brussels } \\
\text { district }\end{array}$ & Movies \\
\hline E-zine 3 & Traveling vouchers & Traffic problems in Brussels & Going out \\
\hline
\end{tabular}

We manipulated the degree of personalization of the lifestyle issues. For each of the three e-zines, the experimental sample was divided in three groups based on their attitudes measured in Phase 1. An article was prepared for the two most popular reply options (high personalization). For the remaining respondents who had not checked one of the two most popular options, a more general article in the same general domain was prepared (low personalization). This was done for each e-zine. As a consequence the composition of these three groups varied from newsletter to newsletter. To investigate the impact of the level of personalization, we counted the number of times each respondent received an e-zine with a highly personalized third article.

The receiver could open the articles by clicking on a link. All online actions were registered. In every e-mail participants were given the chance to opt-out for receiving further e-mails. In total 30 respondents opted-out, leaving 525 respondents for Phase 2.

After the campaign, Phase 2 started, in which all respondents received an e-mail with the second measure of Reichheld's recommendation index. The response rate to this closing mail was rather low: of the 525 e-mails we sent, only 221 (42\%) were filled in; $148(38 \%)$ in the experimental condition and $73(53 \%)$ in the control condition. 
Results

\section{Campaign feedback}

Table 2 Opening Rate and Click Rate as a Function of E-zine

\begin{tabular}{|l|c|c|c|c|}
\hline E-zine & Opening rate & Click rate art 1 & Click rate art 2 & Click rate art 3 \\
\hline E-zine 1 & $238 / 418=56,9 \%$ & $44 \%$ & $34 \%$ & $10 \%$ \\
\hline E-zine 2 & $232 / 405=57,3 \%$ & $59 \%$ & $31 \%$ & $14 \%$ \\
\hline E-zine 3 & $189 / 393=48,1 \%$ & $15 \%$ & $15 \%$ & $16 \%$ \\
\hline
\end{tabular}

The opening rate is defined as the proportion of respondents opening the e-zine. The click rate is the proportion of receivers clicking on a particular article. As the respondents could "opt-out" in every newsletter, the number of e-mails sent off gradually decreases. The opening and click rate in the third e-zine are remarkably lower than in the first and second newsletter. This can be due to the fact that the data registration for this third e-zine was canceled after six days, while for the first two ezines action data were registered for more than two weeks. Moreover, this third e-zine was sent off immediately after a national holiday. The proportion of readers in the first two e-zines, gradually decreases from the first article until the third one. Because click rates strongly depend on the specific topics, we further ignore these differences. 


\section{Reichheld's Recommendation Factor (RF)}

Table 3 Percentage Promoters, Percentage Detractors, Reicheld Factor, and Sample Size as a Function of Phase and Experimental Condition

\begin{tabular}{|c|c|c|c|c|c|}
\hline \multicolumn{2}{|c|}{ Phasel Condition } & \% Promoters & $\%$ Detractors & RF & Sample Size \\
\hline \multicolumn{2}{|l|}{ Phase 1} & 24.1 & 25.5 & -1.4 & 817 \\
\hline \multicolumn{2}{|c|}{ No Approval } & 27.1 & 33.2 & -6.1 & 262 \\
\hline \multicolumn{2}{|c|}{ Approval } & 22.7 & 21.8 & 0.9 & 555 \\
\hline & Control $^{\mathrm{a}}$ & 26 & 20.5 & 5.5 & 73 \\
\hline & Experimental $^{\mathrm{a}}$ & 25 & 18.9 & 6.1 & 148 \\
\hline \multirow{2}{*}{ Phase 2} & Control & 30.1 & 23.3 & 6.8 & 73 \\
\hline & Experimental & 33.1 & 17.6 & 15.5 & 148 \\
\hline
\end{tabular}

Note. ${ }^{\mathrm{a}}$ The respondents of Phase 1 who also responded in Phase 2.

According to their answer on the initial recommendation question (Phase 1), participants were divided in three recommendation categories, labeled as "promoters" (score 9-10), "passively satisfied" (score 7-8), and "detractors" (score 1-6). For the remainder of this article we will refer to this variable as "initial recommendation".

The RF of respondents in Phase 1 was $-1.4 \%$. As top firms with enthusiastic clients reach a RF of $75 \%$, or even more than $80 \%$ (Reichheld, 2001), the Belgian railway company NMBS is doing a bad job when it comes to customers' tendency to recommend the NMBS to others. Further, the test sample $(\mathrm{N}=555)$ that "opts-in" for further contact had a slightly higher RF than those people who did not opt in. It seems reasonable that customers with a higher recommendation index are more likely to volunteer for receiving future e-mail.

Most importantly and in line with our hypothesis, e-zines yield a significant increase of the RF (see Table 3). Before the experimental manipulation, there is no significant difference between the RF of the control and the experimental condition [for $\alpha=.05, \mathrm{Z}=.38<\mathrm{Z}$ (critical) $=1.64]$; whereas in Phase 2 , after the campaign, the RF of the experimental condition is significantly higher than the RF of the control condition 
$[$ for $\alpha=.05, Z=3.95>Z($ critical $)=1.64]$. Table 3 suggests that the decrease of the percentage of brand detractors seems to be responsible for the higher RF of the experimental condition in Phase 2. This pattern is consistent with two of the four possible drivers of the e-zines effect as outlined above. E-zines could either turn detractors into passively satisfied or prevent passively satisfied from becoming detractors. To gain more insights in the four possible drivers of this effect, we examined the effect of the e-zines in each initial recommendation category separately.

\section{The effect of e-zines as a function of initial recommendation}

To analyze the effect of e-zines on recommendation shift, we calculated the difference in the recommendation category between Phase 1 and Phase 2 (see Table 3). Among the passively satisfied customers this shift variable has three levels: (1) customers who make a positive shift in recommendation category (e.g. from initial passively satisfied to promoter after the campaign), (0) customers who make no shift at all, (-1) customers who make a negative shift in recommendation (e.g. from initial passively satisfied to detractor after the campaign). Among the detractors and the promoters, this shift variable has only two levels, since detractors cannot shift downward and promoters can not shift upward.

Among the detractors, the experimental manipulation had a significant effect on the shift in recommendation, $\chi^{2}(2)=4.53, p=.033$. In Phase 2 , there were fewer detractors in the experimental condition than in the control condition. Hence, the detractors who received the e-zines were more likely to shift upward to become passively satisfied or brand promoters, than the detractors in the control condition. Among the initially passively satisfied and the brand promoters the e-zines had no effect on the shift in recommendation, $\chi^{2}(2)<1$, ns. So we can conclude that the e-zines 
have an effect on customers' recommendation, and thus increase the RF, due to a decrease of the brand detractors.

Table 4 Shift in Customers' Recommendation among the Detractors as a Function of Condition

\begin{tabular}{|l|c|c|c|}
\hline Condition & Status quo (0) & Upward shift (1) & N \\
\hline Control Condition & $73 \%$ & $27 \%$ & 15 \\
\hline Experimental Condition & $39 \%$ & $61 \%$ & 28 \\
\hline
\end{tabular}

\section{The effect of opening the newsletters}

Table 5 Number of Customers Opening the Newsletters (Experimental Condition)

\begin{tabular}{|l|c|c|c|}
\hline Exp. Condition & E-zine 1 & E-zine 2 & E-zine 3 \\
\hline $\mathbf{N}=148$ & 117 & 118 & 106 \\
\hline
\end{tabular}

The proportion of customers opening the newsletters is lower for the third ezine (see Table 5). Again, this may be due to the fact that online registrations were closed after six days for this e-zine (while for the first two e-zines action data were registered for more than two weeks) and/or the fact that this e-mail was sent off after a national holiday. In addition, the frequency of sending the e-zines might also have been higher than optimal.

We found no significant correlation between initial recommendation (category) and the number of newsletters actually opened (ranging from 0 to 3 ). This means that the e-zines could equally well reach brand detractors, passively satisfied customers, and brand promoters. We believe that this is an interesting finding, since detractors are usually the skeptical, negative word-of-mouth spreading customers, who are difficult to reach. 
Further, actually having opened the newsletters (from 0 to 3 ) did not have an effect on customer recommendation changes (from -1 to 1 ), $\chi^{2}(6)=3.62$, ns. This means that merely receiving e-zines seems to be enough for detractors to shift upward in recommendation. Whether the newsletters are actually opened or not, does not seem to influence customers' recommendation.

\section{The effect of personalization}

We found a significant negative correlation $(r=-.23, p=.0045)$ between the degree of lifestyle personalization over the three e-zines (ranging from 0 to 3 ) and the shift in recommendation (from -1 to 1). This finding suggests that one should be careful in personalizing e-zines according to the receivers' lifestyle. As we already proposed in our introduction, a strongly personalized e-zine may be interpreted as a marketer's persuasion attempt and therefore slacken the effect of e-zines on customer recommendation (Friestad and Wright, 1994).

\section{Permission marketing: who sticks till the end?}

Of the 555 respondents who in Phase 1 gave permission to use their e-mail address for further contact, only 221 responded to the second measure of Reichheld's recommendation index after the campaign (i.e. closing mail). The initial recommendation (category) does not influence this response rate, $\chi^{2}(2)=2.05$, ns. The initial detractors, the passively satisfied, and the promoters stick equally well until the end of the campaign. We do find a strong association between our experimental manipulation and response rate, $\chi^{2}(1)=13.76, p=.0002$. Customers in the control condition are more likely to respond to the closing mail than customers in the experimental condition (see Table 6). The most likely interpretation is the difference in 
time that had elapsed since the previous e-mail from the company. In the control condition, the closing mail was the first e-mail in 2 months time these customers could respond to, whereas in the experimental condition, the closing e-mail was the fourth email in 2 months time sent off by the same company. In the end, this latter procedure might have been perceived more as "spamming" than as "opt-in" newsletters.

Table 6 Proportion of Customers Responding to the Closing Mail as a Function of Condition

\begin{tabular}{|l|c|}
\hline Condition & Proportion Respondents in Phase 2 \\
\hline Control & $73 / 137=53,3 \%$ \\
\hline Experimental & $148 / 388=38,1 \%$ \\
\hline
\end{tabular}




\section{CONCLUSION}

The research reported examined the influence of e-zines on customers' tendency to recommend a product to others. We found that sending off e-zines increased Reichheld's recommendation factor due to a decrease in the number of brand detractors. The proportion of detractors was significantly lower among respondents who received three e-zines during a 6-weeks campaign compared to respondents in the control condition who did not receive e-zines. In other words, the detractors who received the e-zines were more likely to shift upward to become passively satisfied customers or brand promoters, than the detractors in the control condition. Among the initially passively satisfied and the brand promoters the e-zines had no effect on recommendation changes after six weeks. Therefore, e-zines seem appropriate as a strategic tool to increase customers' collective recommendation.

At first sight, these results suggest that the e-zines milden the negative attitude towards the business, which results in a reduced inclination to spread negative word-ofmouth. However, further analyses strongly suggest that the process underlying this shift is not as straightforward as it seems at first sight. First of all, there was no effect of opening the newsletters on customer's shift in recommendation. Apparently, merely receiving e-zines suffices for detractors to shift upward in recommendation; whether the newsletters are actually opened or not, does not influence customer recommendation shifts. We interpret this surprising finding from a signaling perspective. Nelson (1974) showed that an ad's existence rather than its content matters for consumer. Similarly, the e-zine's existence rather than its content seems to suffice to produce the mildening effect. 
A second finding that does not fit with the straightforward interpretation is the fact that customers' recommendation was negatively affected by the degree of personalization of the life-style article included in each e-zine, as we had predicted. The fewer "personal" articles the customers received, the more likely they were to shift upward in customer recommendation. This is all the more remarkable in light of the fact that almost half of the respondents did not open the newsletters, and because the two first articles dealt with topics that were highly relevant with respect to the company's business. Our data cannot inform us whether the presence of a lifestyle article in itself reduces the positive effects of e-zines. We only know that lifestyle articles reduce the positive effect of e-zines to the extent that they are personalized in line with the respondents' lifestyle. We interpret this finding in the context of the persuasion knowledge model (Friestad and Wright, 1994). We suggest that (lifestyle) personalization activates the customers' persuasion knowledge in that it makes customers aware of the marketer's persuasion attempt and thus leads to a decrease of customer recommendation. High levels of personalization of the third article might also have drawn the attention to the irrelevance of the lifestyle article, which resulted in lower e-zine efficiency. In that sense "relevance" still might play a role here. We do have to note that personalization in function of the respondents' product use or interests in the services of the railway company might have entailed different findings.

Finally, there is a substantial negative effect of the e-zine frequency on customers' recommendation. Customers in the control condition, who received the closing mail two months after the initial contact, were more likely to respond to the closing mail than customers in the experimental condition, who received four e-mails in two months time. A growing problem with permission e-mail is that prospects 
gradually become overwhelmed with an increasing number of e-mails. Perhaps eventually, they may perceive permission e-mail to be spam.

\section{IMPLICATIONS}

The data suggest that e-zines can be an effective tool in increasing customers' recommendation for companies with a high percentage of detractors. This situation probably applies to monopoly organizations because in monopolies detractors cannot substitute suppliers. For this reason, their inclination to show their dissatisfaction by means of negative word-of-mouth might persist longer and do more harm (Fornell, 1992). Our data suggest that for monopolists, e-zines might be an appropriate instrument to restrict the spread of negative word-of-mouth by detractors.

In addition, the converging evidence in our data that our relatively simple campaign was already beyond the optimum in terms of complexity and frequency strongly suggests that the use of e-zines should be used with measure. The 'less is more' rule seems to apply. Since lifestyle-personalization of permission e-zines has a negative effect on customers' recommendation, our data suggest that e-zines' content should be kept general and relevant with respect to the company's business. Since frequency seems to reduce response rate, we propose that one should be careful when deciding on the frequency of sending off e-zines. Permission e-mail seemingly produces much better results than unsolicited mailings. However, as already mentioned earlier, a growing problem with permission e-zines is that many people are signing up for too many services and are finding it necessary to cut back (Dufrene et al., 2005). 


\section{LIMITATIONS AND FUTURE RESEARCH}

A limitation of our research is the type of business used (i.e. public transportation) to test our hypotheses. The railway company NMBS is partly subsidized by the government and is the only railway company in Belgium. This makes it difficult to generalize our findings to other private businesses that are not subsidized and that are not monopolies. We call for future research that investigates the generalizability to other businesses.

Several of our findings call for additional research in the effectiveness of ezines. We found a negative effect of e-zines on response rate but we did not manipulate the frequency of e-zines in our experiment. Further research may give more insight into the optimal frequency of forwarding e-mails. We also found a negative effect of the level of lifestyle personalization but we did not manipulate the number of articles per ezine or the presence of lifestyle issues. A more systematic manipulation of these factors would certainly give us a better understanding of how and when e-zines are an effective tool for marketers to work on customer recommendation. Finally, we found that ezines had a positive effect although many did not open the mail, let alone the articles. An interesting question is how e-zines are processed, and which factors do and do not add to the recommendation shift that we observed.

This research showed no effects on recommendation among the passively satisfied and the brand promoters. However, it would be premature to conclude that ezines do not have an effect at all on these groups. For example, we expect factors such as consumers' prior expectations about a firm to be part of the process. Dawar and Pillutla (2000) found that consumers with positive expectations may provide firms with a form of insurance against the potentially devastating impact of crises; while for 
consumers with weak expectations about a firm, any crisis can be devastating. In that sense, we suggest that e-zines might increase positive expectations about the firm. In normal circumstances (as in our study), the increase in expectations may not be easily observable, at least not among promoters and the passively satisfied. However, the effect of e-zines might only show up in times of crises. It might be the case that promoters are more likely to remain promoters in times of crises when they have received e-zines before the crisis than when they have not. Although this question is more difficult to investigate experimentally, it certainly deserves attention. Also with respect to consumers' expectations, we might have to make a distinction between on the one hand, "real" detractors who already know the firm and have negative expectations, and on the other hand, customers who are "labeled" as detractors because they do not know the firm (and therefore would not recommend it to their friends or family), but still have positive expectations. Perhaps e-zines work especially well for people unfamiliar with the company, as e-zines have the potential to introduce the company's business in a positive light.

An interesting and related avenue for future research would also be to investigate how permission e-mails can be implemented in crisis management and how companies can use this strategy to counter negative publicity. For companies handling a crisis, e-zines might be functional to respond quickly and effectively to maintain consumer confidence in the brand. A study of 2645 consumers by the advertising agency DDB Needham showed that a company's handling of a crisis ranked as the third most important purchase influence (after product quality and handling of complaints) and was mentioned by $73 \%$ of the consumers (Marketing News, 1995). Corporate response to a crisis also appears to be a critical determinant of the impact of the crisis on consumer beliefs that constitute brand equity (Aaker, 1991; Keller, 1993). 
To conclude, we think that this research on permission marketing is still in an early stage and that knowledge about its effects is limited. The results are promising as they suggest that (1) e-zines silence brand detractors and (2) that e-zines should be used with measure. Future research is called for that investigates (1) the role of other factors, such as the relevance of the topics, and e-zine frequency, (2) the generalizability to other market types, and (3) the effect on other dependent variables, such as resistance to attitude change in times of crises. 


\section{REFERENCES}

Aaker, D. A. (1991). Managing Brand Equity: Capitalizing on the Value of a Brand Name. New York: The Free Press.

Cho, C., and Cheon, H. J. (2004). Why do People Avoid Advertising on the Internet?. Journal of Avertising, 33(4), 89-97.

Dawar, N., and Pillutla, M. M. (2000). Impact of Product-Harm Crises on Brand Equity: The Moderating Role of Consumer Expectations. Journal of Marketing Research, 37, 215-226.

Dholakia, U. P., and Bagozzi, R. P. (2001). Consumer Behavior in Digital Environments. Digital Marketing: Global Strategies from the World’s Leading Experts edited by Jerry Wind and Vijay Mahajan, eds., New York: Wiley, 163-200.

DuFrene, D. D., Engelland, B. T., Lehman, C. M., and Pearson, R. A. (2005). Changes in Consumer Attitudes Resulting from Participation in a Permission E-mail Campaign. Journal of Current Issues and Research in Advertising, 27(1).

Fiske, S. T. (1980). Attention and Weight in Person Perception: The Impact of Negative and Extreme Behavior. Journal of Personality and Social Psychology, 38(6), 889906.

Fletcher, K. P., and Peters, L. D. (1997).Trust and Direct Marketing Environments: a Consumer Perspective. Journal of Marketing Management, 13, 523-539.

Fornell, C. (1992). A National Customer Satisfaction Barometer: The Swedish Experience. Journal of Marketing, 56, 6-21.

Friestad, M., and Wright, P. (1994). The Persuasion Knowledge Model: How People Cope with Persuasion Attempts. Journal of Consumer Research, 21, 1-31. 
Keller, K. L. (1993). Conceptualizing, Measuring, and Managing Customer-Based Brand Equity. Journal of Marketing, 57 (1), 1-22.

Krishnamurthy (2001). A Comprehensive Analysis of Permissions Marketing. Journal of Computer Mediated Communication, 6 (January).

Laczniak, R. N., DeCarlo, T. E., and Ramaswami, S. N. (2001). Consumer's Responses to Negative Word-of-Mouth Communication: An Attribution Theory Perspective. Journal of Consumer Psychology, 11(1), 57-73.

Lutz, R. J. (1975). Changing Brand Attitudes through Modification of Cognitive Structure. Journal of Consumer Research, 1, 49-59.

Nelson, P. (1974). Advertising as Information. Journal of Political Economy, 82, 729754.

Reichheld, F. F. (2001). Loyalty Rules! How Today’s Leaders Build Lasting Relationships. Boston: Harvard Business School Press 2001.

Richins, M. L. (1983). Negative Word-of-Mouth by Dissatisfied Consumers: A Pilot Study. Journal of Marketing, 47, 68-78.

Soars, B. (2001). Let's Get Personal. In-Store Marketing, February, 31-34.

Tezinde, T., Smith, B., and Murphy, J. (2002). Getting Permission: Exploring Factors Affecting Permission Marketing. Journal of Interactive Marketing, 16, 28-36.

Wright, P. (1974). The Harassed Decision Maker: Time Pressures, Distractions, and the Use of Evidence. Journal of Applied Psychology, 59, 555-561. 